\title{
DANZAS RITUALES ONUBENSES: UNA SERIE ESCULTÓRICA DE MARTÍN LAGARES
}

\section{RITUAL DANCES FROM HUELVA: A SERIES OF SCULPTURES BY MARTÍN LAGARES}

\author{
Manuel Jesús Carrasco Terriza \\ Academia de Ciencias, Artes y Letras de Huelva. España \\ mj@carrasco-terriza.com
}

\begin{abstract}
Las danzas rituales de la provincia de Huelva forman parte de su patrimonio cultural inmaterial, y han sido catalogadas como bien de interés etnológico. Todas se desarrollan en el marco de celebraciones religiosas festivas, dedicadas a la Eucaristía, a la Virgen o a los santos patronos, acompañando a las procesiones al ritmo del tambor y de la gaita. Consideradas como signo de identidad de sus pueblos, se les han levantado sendos monumentos escultóricos, cinco de los cuales han sido modelados por el artista palmerino Martín Lagares, quien ha sabido reproducir las vestimentas y captar el movimiento de los danzantes.

Palabras clave: danzas rituales; escultura; monumento; Martín Lagares; provincia de Huelva.
\end{abstract}

Ritual dances from the Province of Huelva belong to its intangible cultural heritage and have been classified as property of ethnological interest. All of them take place in the framework of religious festivals devoted to the Eucharist, the Virgin Mary or the patron saints and come along with processions following the rhythm from drums and bagpipes. Regarded as signs of local identity, some sculptural monuments have been erected in their honour. Five of them were sculpted by Martín Lagares, an artist from La Palma del Condado who has been able to reproduce the vestments and capture the movement of the dancers.

Keywords: ritual dances; sculpture; monument; Martín Lagares; Province of Huelva.

\section{INTRODUCCIÓN}

El arte dentro del arte: así se podría calificar la representación plástica de la danza, tema recurrente desde la pintura rupestre hasta nuestros días, y doblemente expresión de los sentimientos humanos, expresados con la corporalidad en 
movimiento al ritmo de la música. Así lo transmiten desde los vasos griegos, las pinturas etruscas, los relieves de bacantes romanas, los niños de las cantorías renacentistas, los alegres aldeanos de Flandes o la refinada aristocracia francesa, hasta Goya, Degas o Matisse.

En el presente artículo tratamos de los monumentos escultóricos realizados por Martín Lagares que inmortalizan algunas de las danzas rituales onubenses. En Escultura mariana onubense ya habíamos recogido las danzas dedicadas a diferentes advocaciones de la Virgen María en Huelva, como parte integrante de las artes que decoran y ennoblecen los cultos a las respectivas imágenes ${ }^{1}$. Con ello nos unimos al homenaje que se tributa al Dr. Juan Miguel González Gómez en su obra escrita y en dos de sus pasiones: la escultura y la provincia de Huelva.

\section{LAS DANZAS RITUALES ONUBENSES}

El territorio onubense cuenta con el más amplio repertorio de danzas religioso-festivas de toda Andalucía: de 22 danzas rituales andaluzas, 14 pertenecen a la provincia de Huelva, que fueron inscritas en 2011 en el Catálogo General del Patrimonio Histórico Andaluz como de interés etnológico ${ }^{2}$. Doce de ellas se ejecutan en diez pueblos de la comarca del Andévalo -Alosno, Cabezas Rubias, El Almendro, El Cerro de Andévalo, Puebla de Guzmán, San Bartolomé de la Torre, Sanlúcar de Guadiana, Villablanca, Villanueva de los Castillejos y Villanueva de las Cruces-y dos en la Sierra-Cumbres Mayores e Hinojales- ${ }^{3}$.

Todas ellas tienen en común interpretarse en el marco de un acto religioso en honor de la Eucaristía en el Corpus Christi, en Cumbres Mayores, o en fiestas patronales, tanto de la Virgen -de la Esperanza, en Cumbres; de Piedras Albas, en El Almendro y Castillejos; de la Tórtola, en Hinojales; de la Peña, en Puebla de Guzmán; de La Rábida, en Sanlúcar-, como de los santos -San Juan Bautista y San Antonio de Padua, en Alosno; San Sebastián, en Cabezas Rubias y Villanueva de las Cruces; San Benito, en El Cerro; San Bartolomé, en San Bartolomé de la Torre-, en las respectivas procesiones, a la salida del templo, en su recorrido por las calles y plazas, o a su término en el interior de las iglesias.

${ }^{1}$ GONZÁLEZ GOMEZ, Juan Miguel y CARRASCO TERRIZA, Manuel Jesús: Escultura mariana onubense. Huelva, 1981, pp. 107-109, 290, 414, 444-445, 447 y 457.

${ }^{2}$ Orden de la Consejería de Cultura de 22 de marzo de 2011, BOJA, 67, 5-4-2011, pp. 56-60.

3 AGUDO TORRICO, J., JIMÉNEZ DE MADARIAGA, C., GARCÍA GALLARDO, F. J. y ARREDONDO PÉREZ, H.: Danzas de la provincia de Huelva. Sevi1la, 2010; y BELZUNCE MANCEBO, Félix: "Las danzas. El festival de Villablanca", en MÁRQUEZ DOMÍNGUEZ, J. A. (dir.): Artes, costumbres y riquezas de la provincia de Huelva. T. IV. Huelva, 1998, pp. 1181-1196. 
La danza es un fenómeno antropológico universal, el arte más antiguo, vinculado a los rituales religiosos e identitarios. Para Colin Quigley, "es el uso creativo del cuerpo humano, en el tiempo y en el espacio, dentro de sistemas culturalmente especificados de estructura y significado del movimiento", "sede importante para configurar y representar identidades étnicas, nacionales y colectivas en general"4. En nuestro caso, el "sistema cultural" es el culto católico y las identidades locales de las comarcas del Andévalo y la Sierra, que tienen posiblemente su origen histórico en los repobladores castellanos.

En la Biblia, la danza era algo más que una simple expresión de alegría popular, sino que tenía su importancia ritual y se practicaba en el templo: "Cantad al Señor un cántico nuevo [...] Alabad su nombre con danzas" (Sal 149, 3)5. Sobre todo es memorable la danza que ejecutó el rey David ante el arca de la alianza, cuando fue trasladada a Jerusalén: "David y toda la casa de Israel bailaban ante el Señor con instrumentos de ciprés, cítaras, arpas, tambores, sistros y címbalos" (2 Sam 6, 5) ${ }^{6}$. La danza es percibida como un acto de obediencia al Señor, para su alabanza y su gloria, un modo de expresión de las emociones religiosas.

En la archidiócesis de Sevilla, las danzas estaban admitidas en las celebraciones religiosas, en torno a las grandes fiestas. Las Constituciones del Arzobispado de Sevilla, del cardenal Niño de Guevara, de 1604, dicen así: "Cosa muy asentada es, por costumbre universal destos reinos de la Corona de Castilla, que la fiesta propia del Santísimo Sacramento (que por lo que en sí contiene se llama de Corpus Christi) se celebre con gran solemnidad y regocijos exteriores de representaciones, danzas y otras cosas; las cuales no es nuestra intención quitar; solamente pretendemos que de tal manera se hagan, que no se ofenda con ellos la Majestad de Dios, sino que se conforme lo exterior con la intención de la Iglesia que las ha permitido [...] Y la misma diligencia mandamos que se haga en las danzas y bailes, porque en ellas no hagan algunos meneos o movimientos deshonestos, que induzcan a pecar"'

La danza aporta al acto de culto la manifestación de una emoción religiosa, seria y acompasada en su recorrido, o contagiosa y desbordante en sus momentos álgidos, en los que se llega al entusiasmo - que en su etimología griega significa "inspiración o posesión divina"-. En la danza se aúnan la fe y la devoción con la música y el ritmo, que se expresan en movimientos corporales. En la danza entran

${ }^{4}$ QUIGLEY, C.: "Danza”, en BARFIELD, Thomas (ed.): Diccionario de Antropología. México, 2000, pp. 146-147.

5 LIPINSKI, E.: "Danza", en Diccionario Enciclopédico de la Biblia. Barcelona, 2003, p. 406. Cfr. Sal 26, 6; 68, 26; 87, 7; 118, 27; 149, 3; y 150, 4 .

${ }^{6}$ Ibidem. Cfr. 2 Sam 6, 14; y 16, 20; y 1 Cró 13, 8.

7 Constituciones del Arzobispado de Sevilla hechas y ordenadas por el Ilmo. y Rvdmo. Sr. D. Fernando Niño de Guevara [...] en la Sínodo que celebró en su Catedral año de 1604. T. II. Sevilla, 1864, pp. 12-13. 
en juego los sentidos del cuerpo y las potencias del alma: la música de la gaita y la percusión del tamboril, de las castañuelas, de los cascabeles o de los palos; la vistosidad de los tejidos en atuendos y tocados; la imaginación que identifica las figuras que diseñan las mudanzas; la fortaleza demostrada en un movimiento continuo a lo largo de horas; la fe expresada en la adoración genuflexa, o en el respeto de no volverle la espalda a la imagen. Junto a esto, el recuerdo de la tradición y el reconocer la propia identidad en la danza ejecutada por los antepasados, y que se abre al futuro con los niños que están tomando el relevo.

Las danzas rituales constituyen una de las señas de identidad más propia de los respectivos pueblos, parte indisociable de sus celebraciones religioso-festivas. De ahí que hayan sido elegidas por sus regidores para ser plasmadas en sendos monumentos escultóricos en los lugares más emblemáticos de los pueblos. En cinco de esos pueblos, las autoridades han acudido al escultor Martín Lagares para que convierta en admirable patrimonio material aquel admirable patrimonio inmaterial.

\section{MARTÍN LAGARES, ESCULTOR}

Nacido en La Palma del Condado (Huelva) en 1976, fue alumno de los salesianos y aprendiz del escultor Joaquín Moreno Daza. Comenzó sus estudios de Bellas Artes en Sevilla y terminó la licenciatura en la Universidad de Cuenca en el año 2000. Desde entonces desarrolla su carrera profesional en su pueblo natal. Martín se ha especializado en la escultura monumental. Trabaja magistralmente el modelado en barro, que gana aún más fuerza táctil cuando se funde en bronce. Su variada obra es de carácter figurativo con un marcado sello personal, que dota a las esculturas de vitalidad propia. Se caracterizan por la variada composición, el modelado suelto y abocetado, la línea serpentinata de las figuras, las formas abiertas, las expresiones llenas de vida interior. Podría decirse que es el artista ideal para representar el movimiento de danza, como efectivamente ha demostrado en los danzantes que ha inmortalizado en esta serie de esculturas.

Gracias a su sólida formación académica, se atreve a afrontar difíciles composiciones, en las que sabe imprimir un grácil movimiento en espiral que parece salir del interior de las figuras, otorgando vitalidad y elegancia al tema tratado. Admiramos en Martín Lagares la correcta proporción, la composición armoniosa, los acertados volúmenes, los vibrantes juegos de luces y sombras, las texturas que parecen llevar marcadas, aún en el bronce, la vigorosa huella de sus dedos. Y no menos que las figuras de bulto redondo, hemos de admirar sus relieves, con espectaculares efectos de perspectiva, que a veces adornan los pedestales de los monumentos, y que contribuyen a crear espacio y movimiento en su entorno.

Además de las figuras de danzantes que nos ocupa, ha realizado más de medio centenar de monumentos, tanto de carácter civil como religioso. Similares a los de los danzantes, en cuanto señas de identidad de los pueblos, recordemos el 
monumento a los Marineros de Punta Umbría, las esculturas ecuestres de las romerías de San Bartolomé de la Torre y de Villanueva de los Castillejos, el del Contrabandista en El Granado, el del Emigrante en San Bartolomé, el del Canastero en Sanlúcar de Guadiana, entre muchos otros. En Moguer tiene el de la procesión de la Virgen de Montemayor, y el de El Tío de las Vistas, en el Centenario de Platero y yo. Además ha realizado varios monumentos dedicados a personas distinguidas que han fraguado la personalidad de los pueblos, en los que hemos de destacar la calidad del retrato y la expresividad de los rostros. Consigue dar nueva frescura a personajes tan conocidos como Federico García Lorca, en San Bartolomé, y Juan Ramón Jiménez, en el hospital de su nombre en Huelva; el retrato de Manuel Siurot y el de su maestro Joaquín Moreno Daza, en La Palma; o el monumento a Diego Franco Izquierdo, en Hinojos, entre otros.

Dentro de la figuración religiosa, merecen mención especial sus trabajos de temática salesiana -María Auxiliadora, San Juan Bosco, etc.-, repartidos por toda la geografía española y en países como Gabón, Togo, Benin o Chile. Entre las imágenes de culto podemos citar el San Leandro de la catedral de Huelva, San Juan Pablo II y Santa Teresa de Calcuta en la parroquia de San Sebastián de Huelva, el grupo de sayones del Cristo de las Cadenas, de Huelva, y últimamente las figuras de San Manuel González para la catedral de Palencia y para San Pedro de Huelva ${ }^{8}$.

En su sencillez personal, no es hombre de honores ni ambiciona premios. Pero es de justicia recordar que le fue otorgado en 2008 el Premio "Jóvenes Investigadores" de la Academia de Ciencias Artes y Letras de Huelva, y que su monumento a Cervantes fue recientemente elegido en concurso para el municipio de Puebla de Cazalla.

\section{CATÁLOGO}

Analizamos seguidamente las cinco esculturas de danzantes, de Martín Lagares, siguiendo el orden cronológico de su ejecución.

\section{Danza de los Palos (2005), Villablanca}

La Danza de los Palos, también llamada Danza de los Pastores o Danza de la Virgen, es la danza ritual en honor a Nuestra Señora de la Blanca, patrona de Villablanca ${ }^{9}$, que celebra su fiesta principal el último domingo de agosto, aunque

${ }^{8}$ Cfr. catálogo de obras en http://www.martinlagares.es/esculturas (Consultado 2411-2016).

9 GONZÁlEZ GÓMEZ, J. M. y CARRASCO TERRIZA, M. J.: Escultura mariana onubense, op. cit., pp. 107-109. 
también se ejecuta el día de San Roque, 16 de agosto $^{10}$. Según se recoge en la catalogación del Patrimonio Histórico Andaluz, la danza, interpretada con palillos y arcos, o sea, palos curvos cubiertos con cintas de colores, la ejecutan tres grupos de danzantes -infantil, juvenil y de mayores-, de número impar, de siete a trece danzantes, que participan en distintos momentos festivos: en el traslado del simpecado de la ermita al pueblo, danza infantil; la tarde-noche del sábado víspera de la romería, danza juvenil; y en la mañana y tarde de la romería, danza de mayores o vieja. Las mudanzas más destacadas son las figuras del arco, el corro, la fila, el cruce de filas, la vuelta, la culebra y la danza en pareja.

Los danzantes visten pantalón de terciopelo azul marino hasta media pierna, camisa blanca, faja de color salmón, medias blancas y zapatillas negras. Al cuello lucen un pañuelo de cachemira y en la cabeza un bonete abierto, puntiagudo por delante, forrado del mismo color salmón con flores y cintas que cuelgan sobre la espalda. Con las manos hacen sonar los palillos y mueven unas varas arqueadas decoradas con cintas y lazadas multicolores, con las que formarán los arcos de honor en algunas de sus mudanzas ${ }^{11}$.

La danza se desarrolla en la plaza de la Constitución, en el camino entre el pueblo y la ermita de Nuestra Señora de la Blanca, en la misma ermita y en su entorno.

La escultura de Martín Lagares representa la figura del manijero en la mudanza llamada "de recogida" (Figura 1). El danzante, agachada la cabeza y sin dejar de mirar al suelo, avanza hasta la imagen, terminando con una genuflexión ante la Virgen, momento de máxima emotividad en el que se lanzan los vivas a la Virgen, a la hermandad y a la propia danza.

El monumento se levanta en la plaza de la Constitución, ante la fachada de la iglesia parroquial, en el centro de una fuente elíptica, sobre un pedestal ochavado, que se decora con cuatro bajorrelieves que reproducen las distintas mudanzas y con cuatro máscaras infantiles a modo de fuente. En una placa se dice: "Siendo Alcalde D. Carlos Pérez-Orta Rubio/ fue inaugurado este monumento a la Danza de los Palos/ por la Teniente de Alcalde Dña. María Jesús Villar Sandá/ el día 17 de marzo de 2005, siendo Martín Lagares el escultor de la obra”.

${ }^{10}$ Cfr. BOJA, 67, 5-4-2011, p. 60; y AGUDO TORRICO, J. et alii: Danzas de la provincia de Huelva, op. cit., pp. 271-293.

${ }^{11}$ GONZÁLEZ GÓMEZ, J. M. y CARRASCO TERRIZA, M. J.: Escultura mariana onubense, op. cit., pp. 107-109. 


\section{Danza de las Espadas (2006), San Bartolomé de la Torre}

La Danza de las Espadas, de San Bartolomé de la Torre ${ }^{12}$, es la danza ritual en honor a San Bartolomé, patrono de la villa, en las fiestas patronales dedicadas al santo el 23 y 24 de agosto, en las vísperas y en la procesión del santo, que se repiten también el 20 de enero en la procesión de San Sebastián, copatrono de la localidad. Los danzantes constituyen un único grupo o coro, formado por un número impar de siete a nueve hombres, destacando el maestro de danza llamado cabeza, y el rabeador que cierra el coro. La danza se interpreta con espadas, de ahí su nombre. Las figuras y mudanzas destacadas son el arco o puente de honor, de rodillas, el cruce en pie, la vuelta simple, el coro, y la cruz.

$\mathrm{La}$ indumentaria, que reproduce Martín Lagares en su escultura -aunque el bronce nos priva del cromatismo-, se compone de camisa blanca, chaleco de terciopelo rojo bordado con hilo negro con motivos geométricos y florales, caireles de plata en lugar de botones, faja verde rematada en tres borlas, pantalón de terciopelo negro, con madroños en la parte inferior, botas camperas y espadas fabricadas exprofeso para este fin. Los colores del chaleco y la faja del maestro son inversos a los del resto.

El ritual de la danza se desarrolla en el ámbito de la iglesia parroquial de San Bartolomé y en el discurrir de la procesión por el entramado urbano. En la víspera del santo, los danzantes recogen a los mayordomos, formando arcos de honor con sus espadas. La evolución completa se realiza en la procesión del 24 de agosto. Dentro de la iglesia se ejecuta la totalidad de las mudanzas, comenzando por la posición de rodillas ante el santo: delante del altar hincan la rodilla derecha, bajando las manos hasta situar las espadas a ras del suelo. Nunca le dan la espalda a la imagen. Con una mano sujetan la empuñadura de la propia espada y con la otra la punta de la del danzante contiguo, formando una cadena que no se romperá en las filas ni en las demás mudanzas.

Martín Lagares ha representado un momento en que el danzante sujeta la espada con ambas manos y levanta el pie, sugiriendo así el movimiento del pequeño salto que marca el ritmo del tamboril y la gaita (Figura 2). Es de destacar la elegante curvatura que se imprime en la figura, contraponiendo la pierna levantada con el torso inclinado.

El monumento se alza en la plaza del Danzador, un espacio urbano ochavado que le sirve de marco, sobre un pedestal rectangular en el que figura la placa: "Danza de las Espadas". Se inauguró en 2006, siendo alcalde Manuel Domínguez.

${ }^{12}$ Cfr. BOJA, 67, 5-4-2011, p. 60; y AGUDO TORRICO, J. et alii: Danzas de la provincia de Huelva, op. cit., pp. 225-247. 


\section{Danza de los Cascabeleros (2007), Alosno}

La danza ritual llamada de los Cascabeleros se ejecuta en honor a San Juan Bautista, patrón de Alosno, en la procesión del 24 de junio ${ }^{13}$. Es realizada por un único grupo de danzantes compuesto por unos diecinueve hombres adultos acompañados durante el desfile procesional por un grupo infantil. Del grupo sobresale el cabeza, cuya función es iniciar la mudanza indicada por el maestro de ceremonias, que desfila junto a los danzantes. En la danza se distinguen dos modalidades: la figura del coro y la danza en fila, durante la procesión. Los cascabeleros interpretan la danza con castañuelas adornadas con cintas blancas, rojas y amarillas, madroños y cascabeles en las tobilleras. Un momento histórico para los cascabeleros tuvo lugar el día 14 de junio de 1993, cuando danzaron ante el papa San Juan Pablo II, abriendo la procesión de las ofrendas en la misa celebrada en Huelva.

La escultura de Martín Lagares recoge la mudanza de la folía, espectacular y llamativa, que se ejecuta como colofón de la danza en coro en el interior de la iglesia parroquial (Figura 3). El cascabelero salta y levanta enérgicamente los brazos para hacer sonar las castañuelas, siempre de cara al santo. Lógicamente, el bronce pierde el colorido de la vestimenta propia, el granate que alude a la sangre del martirio de San Juan Bautista. La indumentaria que aparece en el monumento incluye el calzón con pernera a media pierna con botonaduras en los lados, camisa y cuello de pico, chalequillo de terciopelo, faja en la cintura, banda con la invocación "Viva San Juan Bautista", y medias, con cascabeleras en los tobillos, que dan nombre a la danza.

El monumento está situado en la calle Nueva, en un paseo interior ajardinado. Se eleva sobre un pedestal ochavado, con una placa que dice: "Danza de los Cascabeleros". La inauguración tuvo lugar en junio de 2007, siendo alcalde Benito Pérez.

\section{Danza de los Cirochos (2008), El Almendro y Villanueva de los Castillejos}

La danza de los Cirochos ${ }^{14}$ es una danza ritual religioso-festiva que se ejecuta en honor a la Virgen de Piedras Albas, patrona de El Almendro y de Villanueva de los Castillejos, en el contexto de su romería, que se celebra en la Pascua de Resurrección ${ }^{15}$.

${ }^{13}$ Cfr. BOJA, 67, 5-4-2011, pp. 57-58; y AGUDO TORRICO, J. et alii: Danzas de la provincia de Huelva, op. cit., pp. 33-59.

${ }^{14}$ Cfr. BOJA, 67, 5-4-2011, p. 59; y AGUDO TORRICO, J. et alii: Danzas de la provincia de Huelva, op. cit., pp. 129-149.

${ }^{15}$ GONZÁlEZ GOMEZ, J. M. y CARRASCO TERRIZA, M. J.: Escultura mariana onubense, op. cit., pp. 446-447. 
La danza tiene lugar durante el desarrollo de la romería, el domingo y martes de Pascua de Resurrección. El domingo por la mañana se interpreta la danza acompañando la procesión del Señor Resucitado. Terminada la procesión, ambos pueblos se dirigen al Prado de Osma, en término de El Almendro, donde está enclavada la ermita de la Virgen. Por la tarde, desde la puerta de la ermita los danzadores preceden al paso de la imagen, hasta la Cruz del Calvario, y, al regreso, danzan de rodillas ante la Virgen hasta que llega a la ermita. El martes de romería se repiten los actos, tomando el relevo de la danza el grupo infantil. Vuelve a interpretarse la danza en la novena a la Virgen, en torno al 24 de septiembre, y cuando es llevada la imagen a los dos pueblos, cada siete años. Además, se unen a las fiestas de los patronos, San Sebastián en El Almendro, el 20 de enero, y San Matías en Castillejos, el 24 de febrero.

Los dos grupos de danzantes, de mayores y de niños, están compuestos por un número impar, entre nueve y siete hombres, denominados particularmente cirochos, con castañuelas, mirando hacia las andas de la Virgen. Siendo el paso el mismo siempre, es variable el número de mudanzas: en fila de a uno o de a dos, por fuera, por dentro, la estrella, los cruces, media vuelta y de rodillas. No llevan más instrumentos que las castañuelas en ambas manos, que hacen sonar moviendo los brazos acompasadamente de un lado al otro, al son del tamboril y la gaita.

La indumentaria se compone de pantalón de pana verde oscuro, con seis madroños de lana verdes, rojos y blancos; camisa blanca; faja roja en la cintura; banda roja cruzada en el pecho, recogida bajo el fajín; pañuelo rojo con lunares blancos que cubre la cabeza, anudado en la nuca; medias blancas; zapatillas de esparto blancas, atadas con cintas rojas y verdes; y castañuelas en ambas manos, adornadas con cintas de colores. El guión, o maestro de danza, lleva faja, banda y pañuelo de color verde, en vez de rojo.

El monumento se ubica en el paseo de la Constitución, de Villanueva de los Castillejos, sobre un pedestal ochavado, de granito, con una placa en su frente que dice: "Danza de los Cirochos. Tradicional de Villanueva de los Castillejos El Almendro" (Figura 4). El escultor ha captado el momento en que el danzador levanta su pie izquierdo y contrapone el movimiento con los brazos extendidos a la derecha y la cabeza a la izquierda, formando una composición abierta, en aspas. Fue inaugurado en septiembre de 2008, siendo alcalde Fernando Gómez Martín.

\section{Danza de las Flores o de la Virgen de la Rábida (2011), Sanlúcar de Guadiana}

La danza ritual se realiza en honor de la Virgen de la Rábida, patrona de Sanlúcar de Guadiana, venerada en el templo parroquial de Nuestra Señora de 
la Rábida ${ }^{16}$, en el contexto de las fiestas patronales, que se celebran en torno a la Dominica In Albis, el sábado, domingo y lunes posterior al Domingo de Resurrección ${ }^{17}$.

La danza la ejecutan dos grupos de danzantes de número impar, nueve u once hombres, en el desarrollo de la procesión de la imagen de la Virgen. Visten camisa blanca con botones rojos, faja roja, pantalón de terciopelo negro por debajo de la rodilla con cuatro cascabeles, medias blancas, zapatillas negras anudadas a los tobillos, mantoncillo rojo con flecos que cubre la espalda y medalla de la Virgen. En una mano llevan el arco de madera forrada con tela blanca y flores de papel con colores rosa, blanco, rojo, azul y amarillo, y en la otra las castañuelas o palillos. Mientras danzan, forman una cadena, enlazándose unos con otros por medio del arco. El danzador levanta apenas los pies, dando un pequeño salto, movimiento que se repite caminando, parado y retrocediendo. En el grupo destaca el cabeza, conocido como la cruz, que se distingue por el color amarillo en lugar del rojo. Algunas de las figuras o mudanzas interpretadas son la mudanza de inicio, en el rito de recoger a las autoridades; la genuflexión, cuando la imagen se detiene o está dentro del templo -se aproximan, hincan la rodilla derecha y lanzan los vivas a la Virgen, a la hermandad y al mayordomo-; el arco de honor se forma delante de la iglesia; la espiral, que es la mudanza más vistosa; el doble arco; y los danzantes enfrentados.

El monumento, modelado y vaciado en resina por Martín Lagares, describe la indumentaria del danzante, que porta el arco y las castañuelas, y que levanta el pie en el paso de danza (Figura 5). Se ubica ante la iglesia parroquial, junto a las escalinatas. Fue inaugurado en 2011, siendo alcalde José Manuel Ponce Ojeda.

Fecha de recepción: 2 de enero de 2017

Fecha de aceptación: 20 de enero de 2017

${ }^{16}$ GONZÁLEZ GOMEZ, J. M. y CARRASCO TERRIZA, M. J.: Escultura mariana onubense, op. cit., p. 457.

${ }^{17}$ Cfr. BOJA, 67, 5-4-2011, p. 60; y AGUDO TORRICO, J. et alii: Danzas de la provincia de Huelva, op. cit., pp. 249-267. 


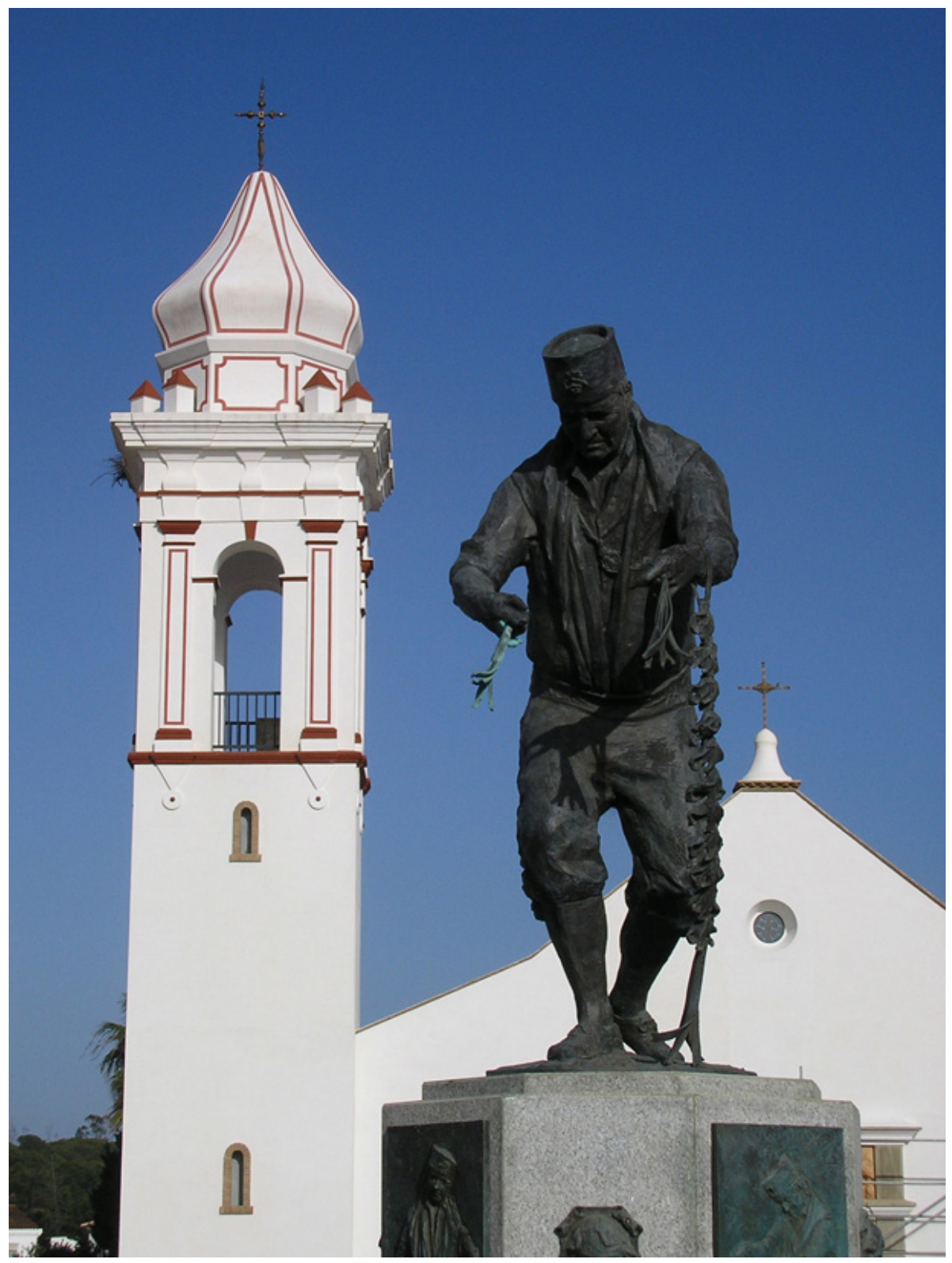

Figura 1. Martín Lagares, Danza de los Palos, 2005, Villablanca (Huelva). 


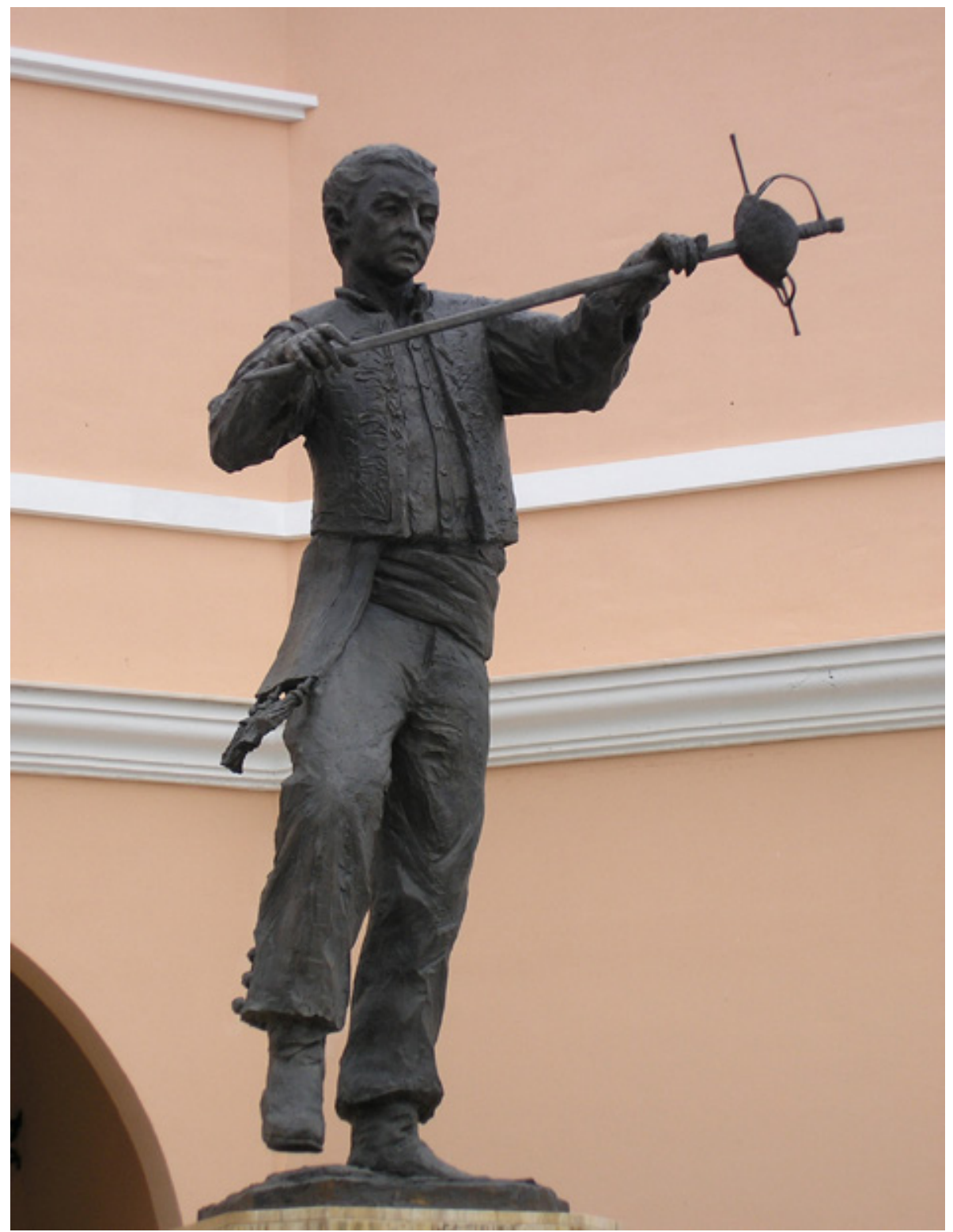

Figura 2. Martín Lagares, Danza de las Espadas, 2006, San Bartolomé de la Torre (Huelva). 


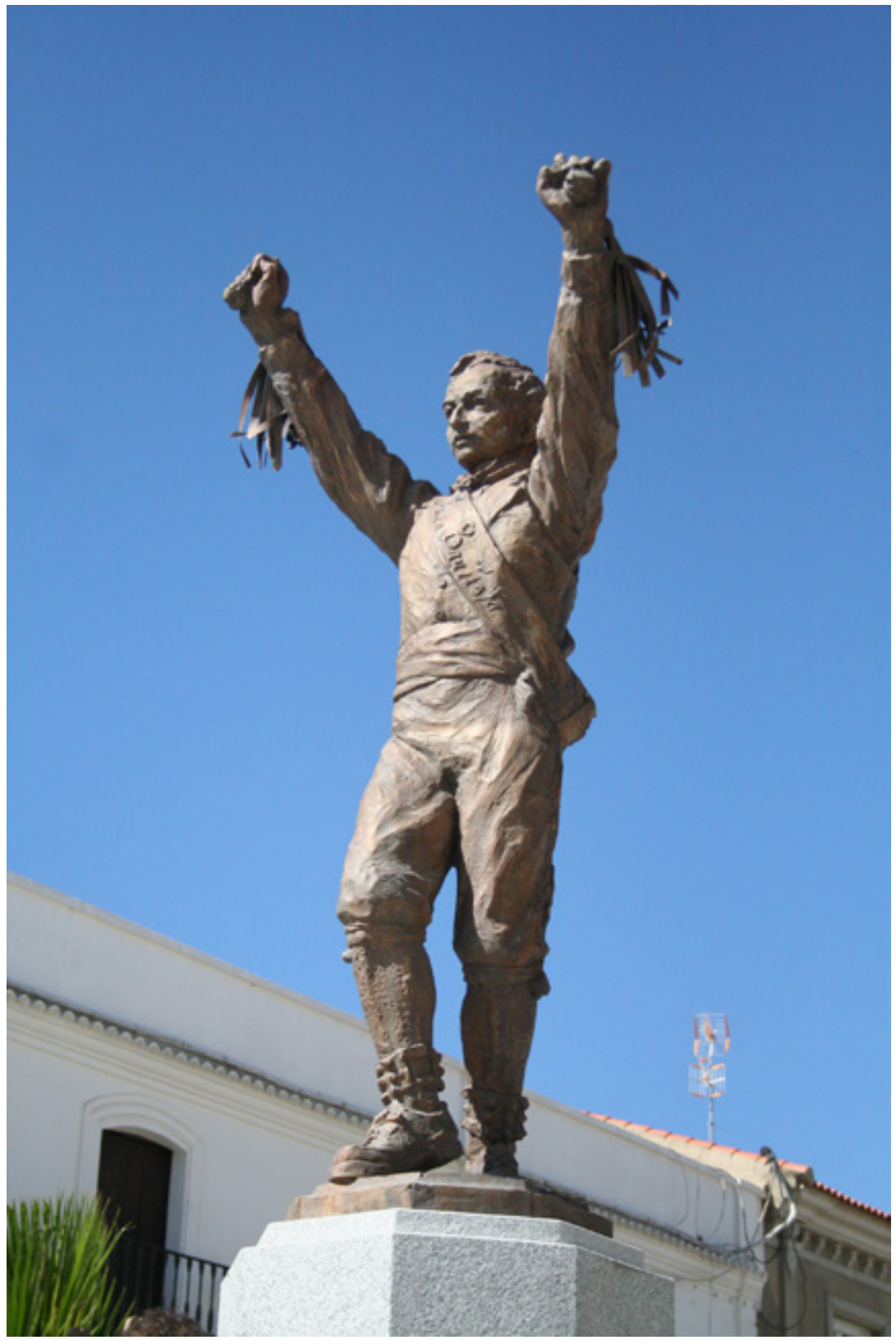

Figura 3. Martín Lagares, Danza de los Cascabeleros, 2007, Alosno (Huelva).

LABORATORIO DE ARTE 29 (2017), pp. 777-791, ISSN 1130-5762 e-ISSN 2253-8305 - DOI http://dx.doi.org/10.12795/LA.2017.i29.42 


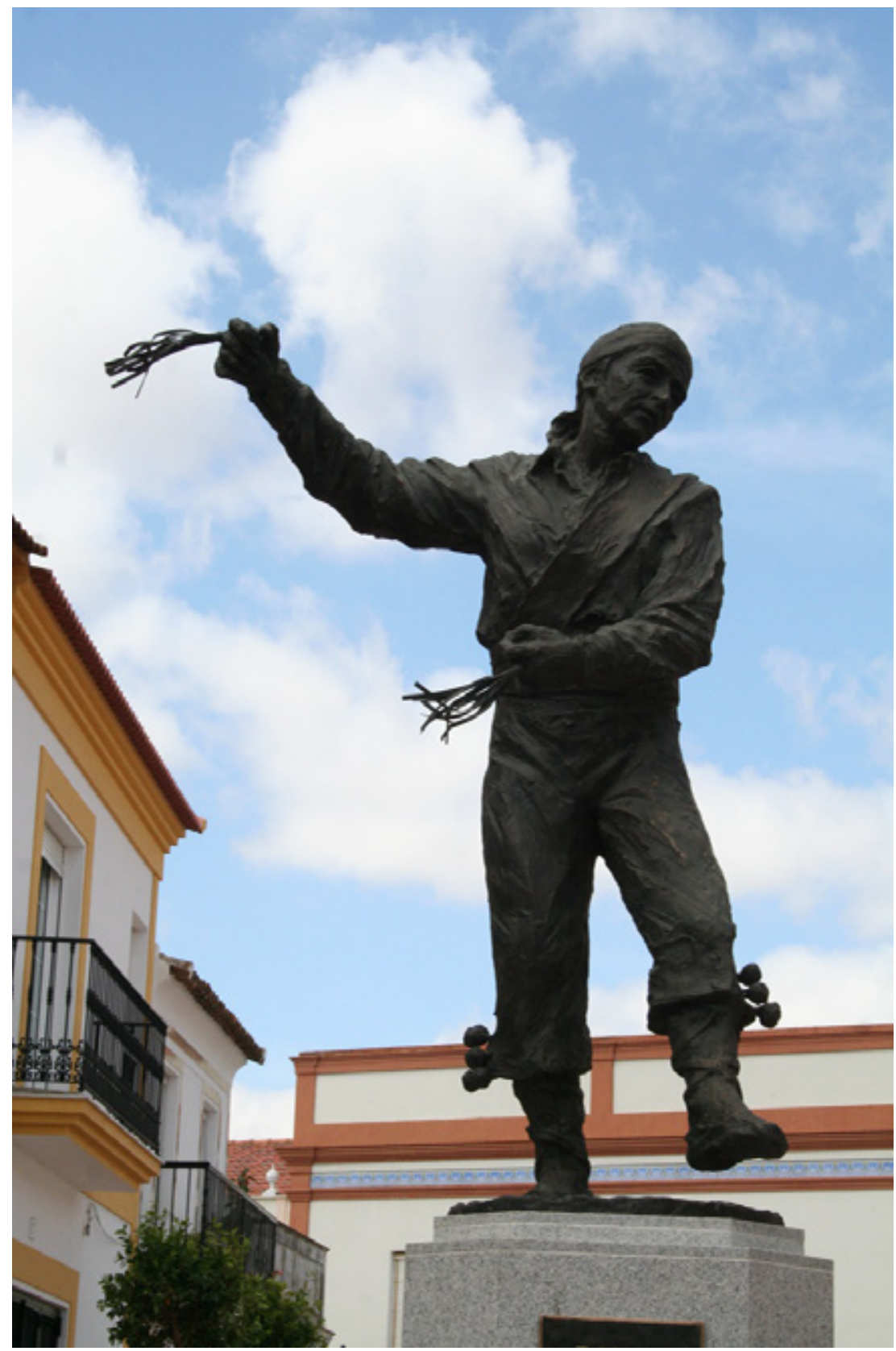

Figura 4. Martín Lagares, Danza de los Cirochos, 2008, Villanueva de los Castillejos (Huelva). 


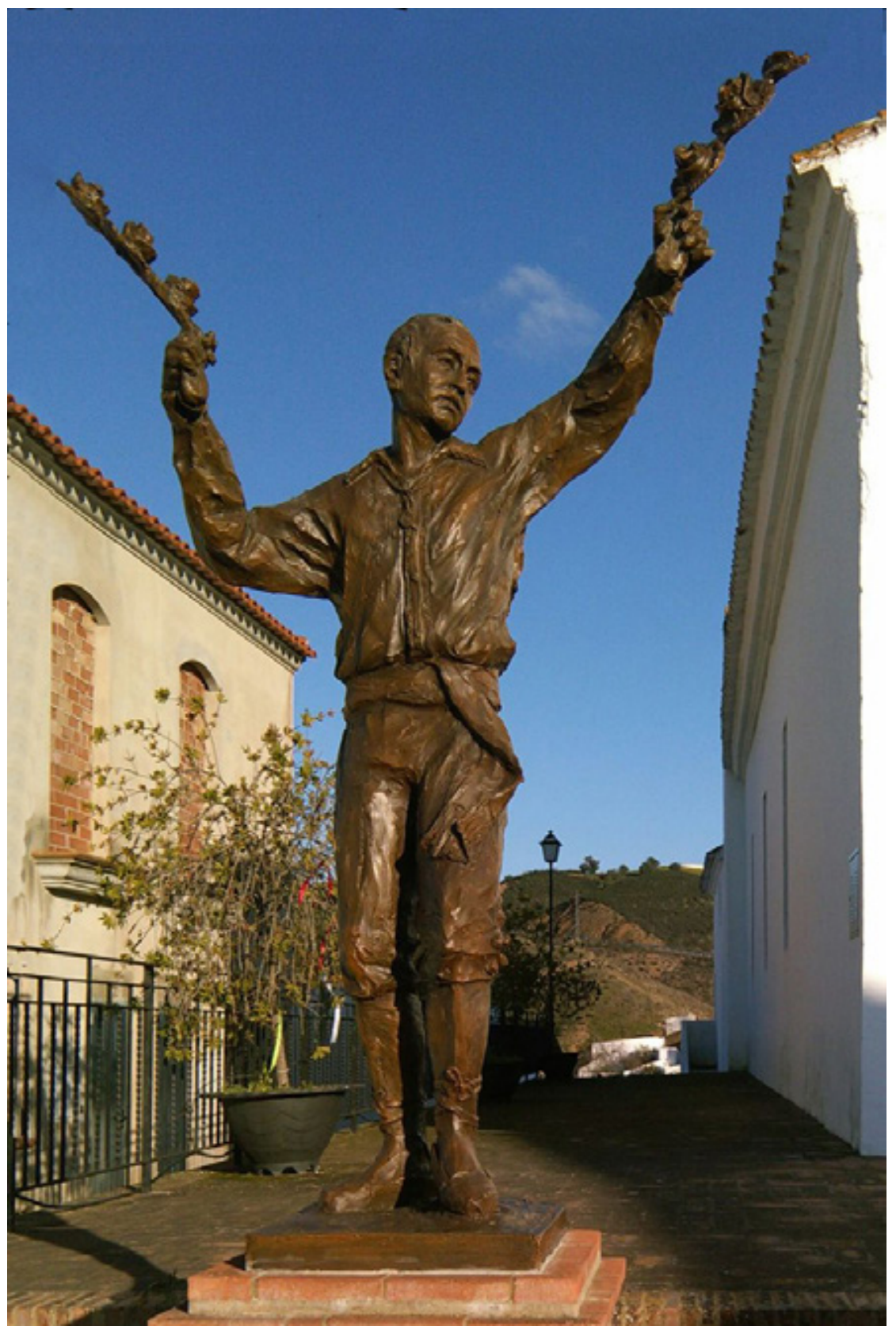

Figura 5. Martín Lagares, Danza de las Flores o de la Virgen de la Rábida, 2011, Sanlúcar de Guadiana (Huelva).

LABORATORIO DE ARTE 29 (2017), pp. 777-791, ISSN 1130-5762 e-ISSN 2253-8305 - DOI http://dx.doi.org/10.12795/LA.2017.i29.42 